\title{
Development of PCR-based Fingerprinting Tool in Banana (Musa sp., AAA) and Conversion of Negative to Positive DNA Marker
}

\author{
Reynato P. Umali ${ }^{1}$, Nanako Kameya, and Ikuo Nakamura \\ Graduate School of Science and Technology, Chiba University, 648 Matsudo, \\ Matsudo City, Chiba 271-8510, Japan
}

Additional index words. RAPD, DNA fingerprinting, arbitrary primer, PS-ID, $r p l$ gene

\begin{abstract}
The banana (Musa sp., AAA) genome is continuously expanding due to the high frequency of somaclonal variation. Because of this increasing diversity, numerical and morphological methods of taxonomic and phylogenetic identification of banana cultivars became laborious, difficult, and often the subject of disagreements. The aim of this study, therefore, is to develop molecular tools for DNA fingerprinting that can discriminate Musa, AAA Cavendish subgroup cultivars. In this paper, we showed that the plastidsubtype identity (PS-ID) sequence of the noncoding region between $r p l 16$ and $r p l 14$ genes of plastid DNA was highly conserved except for single-base substitution and deletion. These differences separated the clones into three groups (G1, G2, and G3) and suggested that clones within groups are closely related maternally. Using arbitrary primer A13, we later identified negative RAPD markers $\mathrm{A}^{13}{ }^{3.0}$ and $\mathrm{A}^{13}{ }^{1.3}$ specifically for $\mathrm{S} 4$ (selection from Giant Cavendish subgroup, AAA) and S11 ('Morado' from 'Red' and 'Green Red' subgroup, AAA), respectively. Fragments corresponding to the missing bands were sequenced and used as templates to design new primers with overlapping sequences. Two of these primers, $\mathrm{Ba3.0A}$ and $\mathrm{Ba} 1.3 \mathrm{~A}$, successfully generated positive markers consistently amplified as $\mathrm{Ba3.0A}^{0.8}$ and $\mathrm{Ba} \mathrm{BA}^{0.6}$ for $\mathrm{S} 4$ and $\mathrm{S} 11$, respectively. It is proposed that the method just described can be a better alternative over screening more arbitrary primers in generating positive markers in cases when negative ones were already identified. Results of PS-ID subtype analysis likewise suggested potential use in identifying wild maternal progenitor in polyploid bananas.
\end{abstract}

Conventional breeding of Musa, AAA Cavendish subgroup bananas is not normally feasible because these triploids are totally sterile and seedless (Lysak et al., 1999; Robinson, 1996). Some triploid AAA bananas, however, like Gros Michel (Shepherd, 1954) can produce seeds when pollinated. Seed set and germination, however, are very low. In spite of this, Musa sp. genome is continuously expanding due to the high frequency of somatic mutation. Being the favored method of seedling production, in vitro propagation of banana using isolated buds and meristem can result in the production of high numbers of somaclonal variants, ranging from $3 \%$ to $25 \%$ (Drew and Smith, 1990; Hwang and Ko, 1987; Stover, 1987). Obviously, somatic mutation becomes the major contributor in increasing the number of banana clones. Difficulty arises in discriminating between clones especially when morphological differences are not visibly significant (Robinson, 1996).

Received for publication 16 Apr. 2001. Accepted for publication 15 March, 2002. We thank Dr. Masahiro Mii and Dr. Yoshihiro Ueda of Graduate School of Science and Technology, Chiba University, for the critical review of the manuscript. Likewise, we are grateful to Stanfilco-Division of Dole Philippines, Inc., for providing the germplasm used in this study.

${ }^{1}$ E-mail address: rpumali@green.h.chiba-u.ac.jp
Early taxonomic and phylogenetic determinations within the genus Musa were largely established using a numerical, morphologybased scoring system (Simmonds and Weatherup, 1990). Within this system, however, the classification and relationships of some genotypes are disputed (Gawel and Jarret, 1991). Isozymes were the first molecular markers to be used in plant breeding programs for screening lines and tagging chromosomes (Chevre et al., 1991); but some researchers have found that the various isozyme markers are not generally suitable for distinguishing between Musa clones of the same genome group and ploidy level (Robinson, 1996). Similarly, restriction fragment length polymorphism (RFLP) can detect differences in the length of digested fragments that hybridize with a known DNA probe. This hybridizationbased tool has been used to distinguish the genotype of plants such as rice (Oryza sativa L.; Winberg et al., 1993), bean (Phaseolus vulgaris L.; Stockton et al., 1992) and banana (Bhat et al., 1994; Gawel and Jarret, 1991). However, aside from using radioactive material, the method is laborious, time consuming, and expensive to perform (Ford-Lloyd, 1996).

On the other hand, polymerase chain reaction (PCR)-based techniques, such as random amplified polymorphic DNA (RAPD), have become popular in many laboratories. Since RAPD analysis can amplify unknown seg- ments of DNA using one or two short arbitrary primers (Williams et al., 1990), the RAPD bands obtained are used as dominant markers (Michelmore et al., 1991). For example, the DNA marker for dwarf off-types from micropropagated Cavendish (Damasco et al., 1996) and plantain (Ford-Lloyd et al., 1993) bananas were identified by this method. PCR techniques involve the design of arbitrary primers (Innis et al., 1999; Williams et al., 1990) that discriminate annealing sites. The key, therefore, is to look for the presence of specific sequences or combinations of sequences where specific primers will preferentially bind to produce a banding pattern that uniquely identifies an organism (Henry, 1997). These different sequences scattered throughout the genome constitute a genetic fingerprint that can discriminate individual cultivars.

Fingerprinting can be used to detect parental genotypes with reduced number of progeny populations that need to be generated during hybridization (Crouch et al., 1999). More importantly, DNA fingerprinting techniques have been used for various applications, including but not limited to identification of species and cultivars (Henry, 1997), identification of duplications among accessions in the field and in tissue culture germplasm banks, monitoring of genetic stability in micropropagated material, selection of key markers suitable for breeding programs, to police plant patents, and to protect rights for newly bred cultivars (Robinson, 1996).

This study was carried out to show possible maternal relationship among selected banana (Musa sp.) clones using PS-ID (plastid-subtype identity) sequence analysis (Nakamura et al., 1997) and to describe a method for converting a negative into a more reliable positive DNA marker.

\section{Materials and Methods}

Plant material. Leaf samples from a total of 15 (eleven 3x, AAA; two $2 \mathrm{x}$, AA; one $3 \mathrm{x}$, $\mathrm{AAB}$ and one $4 \mathrm{x}, \mathrm{AAAB}$ ) dessert and cooking banana cultivars (see Table 1) were generously provided by Stanfilco-Division of Dole Philippines, Inc., in Davao City, Philippines. Total genomic DNA was initially isolated using CTAB (Cetyltrimethylammonium bromide) method from $2 \mathrm{~g}$ of frozen banana leaf tissues. DNA samples were re-extracted with chloroform before resuspending the samples in TE (10 mm Tris-HCl, 1mm EDTA, $\mathrm{pH} 8.0)$ buffer.

Plastid-subtype identity (PS-ID) analysis. PS-ID (plastid-subtype identity), which is a nucleotide sequence from the stop codon of rpl16 to the start codon of rpl14 genes of plastid DNA (Fig. 1) was analyzed as described by Nakamura et al. (1997). A PCR amplification of the plastid DNA fragment containing $r p l 16$ and $r p l 14$ was performed using one pair of common primers A ( $5^{\prime}$-AAA GATCTAGATTTCGTAAACAACATAGA GAAGAA-3') and B (5'-ATCTGCAGCATT TAAAAGGGTCTGAGGTTGA ATCAT-3'). The $P C R$ reaction mixture of $25 \mathrm{~mL}$ contained 1x Taq DNA polymerase buffer, $0.2 \mathrm{~mm}$ 
dNTPs, $10 \mathrm{ng}$ of primers, $1.5 \mathrm{U}$ of Ex Taq DNA polymerase (Takara Biomedicals, Shiga, Japan) and 10-50 ng of total genomic DNA as template. Amplification was conducted with 35 cycles of the following thermal conditions: $1 \mathrm{~min}$ at $94^{\circ} \mathrm{C}, 1 \mathrm{~min}$ at $52^{\circ} \mathrm{C}$, and $2 \mathrm{~min}$ at 72 ${ }^{\circ} \mathrm{C}$ using a DNA engine (PT-200; MJ Research, Watertown, Mass.). Amplified fragments were purified by a PCR purification kit (Promega Corp., Madison, Wis.) and were directly sequenced from both strands using A or $\mathrm{B}$ primer with a PRISM dye terminator cycle sequencing kit using 373A sequencer (Applied Biosystems, Foster City, Calif.).

$R A P D$ fingerprinting. PCR was carried out on eight AAA cultivars using 50 random oligo 10-mer (OPA01-10, OPB01-10, OPC01-10, OPD01-10, and OPE01-10, Operon; Qiagen Gmbh, Germany) and twenty 12-mer (CMN A00-A19, Bex Co., Tokyo) primers. Reaction mixture of $25 \mathrm{~mL}$ contained 1x Taq DNA polymerase buffer, $0.2 \mathrm{~mm}$ dNTPs, $10 \mathrm{ng}$ of primers, $1 \mathrm{U}$ of Ex Taq DNA polymerase (Takara Biomedicals) and 10-50 ng of total genomic DNA as template. Amplification was carried out at $94^{\circ} \mathrm{C}$ for $2 \mathrm{~min}$, followed by 35 cycles of $1 \mathrm{~min}$ at $94^{\circ} \mathrm{C}, 1 \mathrm{~min}$ at $42^{\circ} \mathrm{C}$, and 2 min at $72^{\circ} \mathrm{C}$ using a DNA engine (PT-200, MJ Research). Annealing temperature was adjusted depending on primer sequence. Amplified products were separated in $1.2 \%$ agarose gel, photographed under ultraviolet (UV) light and screened for specificity to a particular cultivar.

Conversion of negative into positive DNA marker. Polymorphic bands (A13 $3^{1.3}$ and $\mathrm{A} 13^{3.0}$ ) from the initial RAPD experiment (see Fig. 2) were first isolated from agarose gel and purified using gel purification kit (Qiagen Gmbh). Purified fragments were then sequenced using PRISM dye terminator cycle sequencing kit using a 373A sequencer (Applied Biosystems). Nucleotide sequences were inputted in a computer as templates to design new oligonucleotide primers using PRIMER3 software (Rozen and Skaletsky, 1998). Primers were chosen such that each primer sequence overlaps "walks" along the template DNA without forming primary and secondary structures. A total of five new primers were later used to amplify genomic DNA samples. Amplification condition was modified to $94{ }^{\circ} \mathrm{C}$ for 2 min followed by 38 cycles of $30 \mathrm{~s}$ at $94^{\circ} \mathrm{C}, 30 \mathrm{~s}$ at $55^{\circ} \mathrm{C}$, and $1 \mathrm{~min}$ at $72^{\circ} \mathrm{C}$ using a DNA engine (PT-200, MJ Research). Annealing temperature was adjusted depending on primer sequence. PCR reaction was carried out in $25 \mathrm{~mL}$ solution containing 1x Taq DNA polymerase buffer, $0.2 \mathrm{~mm}$ dNTPs, 50 pmol primer, $1.5 \mathrm{U}$ of Ex Taq DNA polymerase (Takara Biomedicals) and $10-50 \mathrm{ng}$ of total genomic DNA as template. Amplified products were separated electrophoretically in $1.0 \%$ agarose and $1 \mathrm{x}$ TAE buffer. Gels were stained with ethidium bromide and photographed under UV light.

\section{Results and Discussion}

Plastid-subtype identity (PS-ID) of different banana cultivars. Plastid genome shows simple inheritance in that it is usually transmit-
Table 1. Musa germplasm used for plastid sub-type identity (PS-ID) and random amplified polymorphic DNA (RAPD) analyses.

\begin{tabular}{|c|c|c|c|c|}
\hline $\mathrm{No}^{\mathrm{z}}$ & Cultivar/Clone & Genome & Origin/source & Use of fruit \\
\hline$\overline{\mathrm{S} 1}$ & Giant Cavendish & AAA & General & Dessert \\
\hline $\mathrm{S} 2$ & Umalag & AAA & Philippines & Dessert \\
\hline S3 & Ecuador Dwarf & AAA & L. America & Dessert \\
\hline S4 & Giant Cavendish ${ }^{y}$ & AAA & Philippines & Dessert \\
\hline S5 & Short Williams & AAA & Aus/S.Africa & Dessert \\
\hline S6 & Short Williams & AAA & Philippines & Dessert \\
\hline S7 & Tall Williams & AAA & Aus/S.Africa & Dessert \\
\hline S8 & Valery & AAA & L.America & Dessert \\
\hline S9 & Giant Cavendish ${ }^{\mathrm{x}}$ & AAA & Philippines & Dessert \\
\hline S10 & Lakatan & AAA & Philippines & Dessert \\
\hline S11 & Morado & AAA & Philippines & Dessert \\
\hline $\mathrm{S} 12$ & Liswi & AA & Philippines & Dessert \\
\hline S13 & Orito & AA & Ecuador & Dessert \\
\hline S14 & Tanduk & $\mathrm{AAB}$ & Philippines & Cooking \\
\hline S15 & Goldfinger & AAAB & FHIA $^{w}$ & Dessert \\
\hline
\end{tabular}

${ }^{\mathrm{z}}$ Serial numbers referred to in the paper.

${ }^{\mathrm{y}, \mathrm{x}}$ Giant Cavendish selections.

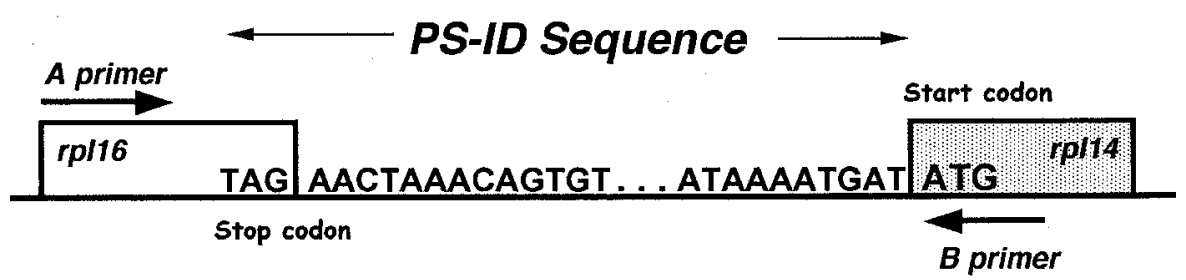

Fig. 1. Schematic representation of plastid sub-type identity (PS-ID) sequence analysis (Nakamura et al., 1997). PS-ID sequence is a short $3^{\prime}$ noncoding sequence from the stop codon of the $r p l 16$ to the start codon of $r p l 14$ gene of plastid DNA which can be amplified and sequenced using common (A and B) primers as shown in the figure.

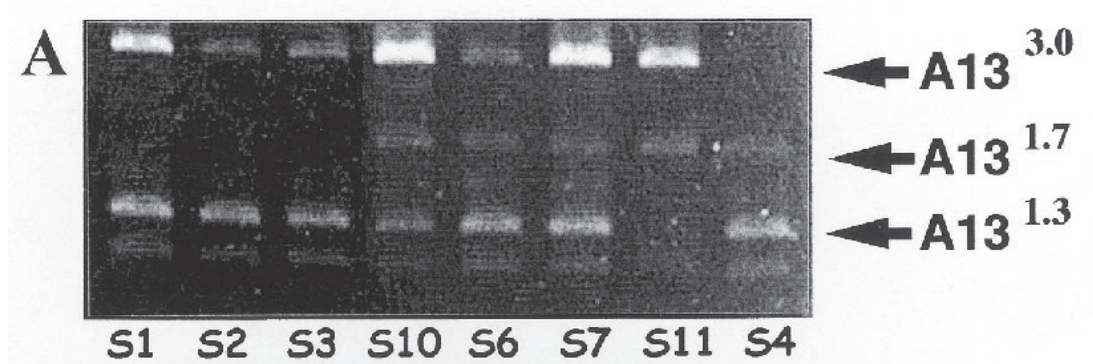

B

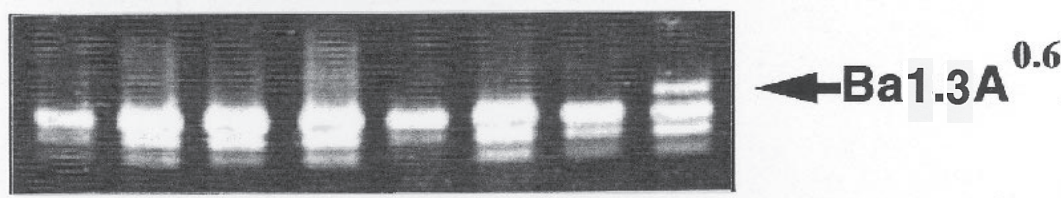

$\mathrm{C}$

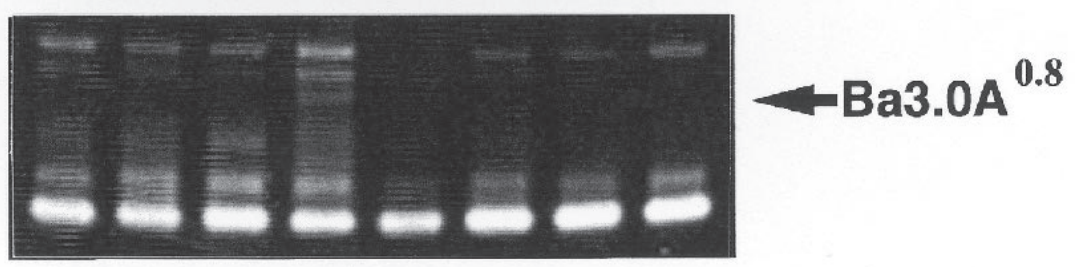

$\begin{array}{llllllll}51 & 52 & 53 & 54 & 510 & 56 & 57 & 511\end{array}$

Fig. 2. RAPD fingerprints of Musa sp., AAA cultivars. Shown are negative markers $\mathrm{A} 13^{1.3}$ for $\mathrm{S} 11$ and $\mathrm{A} 13^{3.0}$ for S4 (A), while positive markers derived from these fragments are $\mathrm{Ba}^{2} .3 \mathrm{~A}^{0.6}(\mathbf{B})$ and $\mathrm{Ba} .0 \mathrm{~A}^{0.8}(\mathbf{C})$, respectively. 
Table 2. Alignment of Musa sp. PS-ID sequences.

\begin{tabular}{lrlcr}
\hline \hline Group $^{z}$ & & & PS-ID Sequence $^{y}$ \\
\hline All cultivars & 1 & TAGAACTAAACAGTGTATTGAGGATGAAAAAACAACGGCAAGTTTATTTATTTCTGGACA & 60 \\
\hline G1 & 61 & GAGAATATTTCTTTTTTCCTTCATCCTTTGCATTAAAATAACGGATTCCAATAAAATGAT & 119 \\
G2 & 61 & GAGAATATTTCTTTTTCCTTCATCCTTTGCATTAAAATAACGGATTCCAATAAAAAGAT & 119 \\
G3 & 61 & GAGAATATTTCTTTTTCCTTCATCCTTTGCATTAAAATAACGG_TTCCAATAAAATGAT & 118 \\
& & & $\star$
\end{tabular}

${ }^{2}$ G1 grp: S1, S4, S5, S6, S7, S8, S9, S10, S11, S13, S14, and S15; G2 grp: S2 and S12; G3 grp: S3.

y Underlined letters indicate stop codon of $r p l 16$ gene on each plastid DNA while asterisks $(*)$ indicate locations of base differences within PS-ID sequence.

ted maternally in most plant species (Liu and Musial, 2001), and that the protein coding sequences change more slowly (Clegg, 1993). This property therefore makes organelle DNA ideal material for identifying the maternal parents of polyploid species (Liu and Musial, 2001). Different parts of chloroplast genome however evolve at different rates. The coding sequences of the $r p l 16$ and $r p l 14$ genes for example were highly conserved $(85 \%$ and $84 \%$ homology, respectively), whereas the linker sequences showed only $28 \%$ homology among rice, spinach, and tobacco (Nakamura et al., 1997). For this reason, the linker region was chosen to address the plastid subtype of different banana cultivars in this study.

Alignment of plastid subtype identity (PSID) sequences showed that banana cultivars listed in Table 1 can be classified into one major (G1) and two minor (G2 and G3) groups (Table 2). Except for S2, S12, and S3, the remaining 12 cultivars had the same PS-ID sequences. When compared with G1, the PSID of $\mathrm{G} 2$ has one base substitution from $\mathrm{T}$ to $\mathrm{A}$ at nucleotide position 116, while G3 showed one base deletion at position 104. Interestingly, S2 a 3x, AAA has the same PS-ID as S12, which is $2 \mathrm{x}$, AA (Table 2). In addition, $\mathrm{S} 15 \mathrm{a} 4 \mathrm{x}, \mathrm{AAAB}$ has the same PS-ID as the rest of $3 x$, AAA cultivars in G1 group. Origin of S15, however, showed that it was derived from a cross between a selected diploid breeding line SH 3142 (AA) and a dessert triploid (AAB) female parent Prata Ana (Robinson, 1996), whose maternal origin most likely was a diploid AA. This is because triploidy in banana is thought to have arisen following the fertilization of viable, diploid egg cells, which can be formed when meiosis breaks down at the second division, with haploid pollen (Simmonds, 1962). This may also explains why S14 that belonged to AAB plantain has identical PS-ID to the rest of the G1 group. This makes sense, since $\mathrm{AAB}$ can be formed by fertilization of diploid $\mathrm{AA}$ or $\mathrm{AB}$ egg cell by haploid $\mathrm{BB}$ pollen where $\mathrm{AA}$ and $\mathrm{AB}$ maternal parents were both fertile diploid AA cultivars. These findings therefore suggest that cultivars within each group are closely related and probably originated from the same maternal lineage.

This single-base polymorphism is nevertheless expected, since chloroplast genome is considered to be conservative in its evolution; it is structurally conservative and evolves fairly slowly at the nucleotide sequence level (Downie and Palmer, 1992). Early efforts to model sequence evolution also assumed that all sites had an equal probability of substitution, that change between any two nucleotides was equiprobable, and that the processes responsible for change were stochastic (Fitch, 1971).

Identification of sequence divergence like this among populations and subspecies can be useful for the selection of genetically important species for conservation and breeding purposes. Likewise, breeding would be greatly simplified if the wild progenitors of cultivated bananas and plantains were to be identified (Lysak et al., 1999). Provided that all putative wild progenitors of modern bananas still exist, it becomes interesting to compare their PS-ID subtypes to show possible maternal origin of polyploid banana cultivars.

RAPD Fingerprinting of Musa sp. Genomic DNA of some of the clones examined did not amplify any product and has to be reextracted with chloroform to remove possible polymerase inhibitors. Intensity of the bands was improved when concentrations of Taq polymerase and primers were elevated from 1 to $1.5 \mathrm{U}$ and from 10 to $50 \mathrm{pmol}$ per reaction, respectively. Only products consistently amplified in separate reactions were further screened for cultivar specificity. As a result, only A13 appeared to be specific to particular clones among the original arbitrary primers used (Fig. 2A). Fragments A13 $3^{1.3}$ and A13 $3^{3.0}$ were consistently absent only in S11 and S4, respectively. However, A $13^{1.3}$ and A $13^{3.0}$ were negative markers and therefore less specific to reliably discriminate between clones. Considering the common PCR conditions used, the absence of these bands indicates that there is an absence or low level of homology between the primers and the template DNA of S4 and $\mathrm{S} 11$ cultivars. One alternative therefore aside from screening another set of random primers is to sequence the fragments corresponding to these bands and use them as templates to design more specific primers.

Conversion of negative to positive marker. Among the five new primers derived from polymorphic A13 fragments, two were able to amplify scorable bands. Primers Ba1.3A (5'TTCCCTACCCTCTAAATGAGATGTTCC AAGCAACCAAAG-3') and Ba3.0A (5'CGCTAAGTGAATGAGTTCGGGTCAA GAAGC-3') were able to resolve a maximum of five and six bands respectively (Fig. 2). As shown earlier, A13 $3^{1.3}$ fragment (used as template for Ba1.3A primer) was consistently absent in S11. Using Ba1.3A primer, however, Ba1.3A $\mathrm{A}^{0.6}$ was later amplified as a positive marker specifically for S11 (Fig. 2B). In the same manner, $\mathrm{A} 13^{3.0}$ fragment (used as template for $\mathrm{Ba} 3.0 \mathrm{~A}$ primer) that is originally absent in $\mathrm{S} 4$, was later amplified as $\mathrm{Ba} 3.0 \mathrm{~A}^{0.8}$
(Fig. 2C). This result apparently confirmed that the initial absence of the same band could indicate low level of association, or to the loss of, or mutation in, regions homologous to the original primer sequences (Crouch et al., 1999).

While SCAR (sequence characterized amplified region) allows the design of longer specific primers for the amplification at the same locus (Henry, 1997), the method described herein used the sequence of a negative marker as template to design new primers to generate a unique band specific to cultivars. Furthermore, since the resulting positive marker can be sequenced and longer primer pair can be designed, this marker like SCAR can become highly reproducible to discriminate S4 and S11 from among morphologically indistinguishable cultivars.

\section{Literature Cited}

Bhat, K.V., R.L. Jarret, and Z.-W. Liu. 1994. RFLP characterization of Indian Musa germplasm for clonal identification. Euphytica 80:95-103.

Chevre, A.M., P. This, F. Eber, M. Deschamps, M Delseny, and C.F. Quiros. 1991. Characterization of disomic addition lines Brassica napusBrassica nigra by isozyme, fatty acids and RFLP markers. Theor. Appl. Genet. 81:93.

Clegg, M.T. 1993. Chloroplast gene sequences and the study of plant evolution. Proc. Natl. Acad. Sci. USA. 90:363-367.

Crouch, J.H., H.K. Crouch, H. Constandt, A. Van Gysel, P. Breyne, M. Van Montagu, R.L. Jarret, and R. Ortiz. 1999. Comparison of PCR-based molecular marker analyses of Musa breeding populations. Mol. Breed. 5:233-244.

Damasco, O.P., G.C. Graham, R.J. Henry, S.W Adkins, M.K. Smith, and I.D. Godwin. 1996 Random amplified polymorphic DNA (RAPD) detection of dwarf off-types in micropropagated Cavendish (Musa spp., AAA) bananas. Plant Cell Rpt. 16:118-123.

Downie, S.R. and J.D. Palmer. 1992. Use of chloroplast DNA rearrangements in reconstructing plant phylogeny, p. 2. In: D.E. Soltis, P.S. Soltis, and Doyle J.J. (eds.). Molecular systematics of plants II. Kluwer Acad. Publ., London.

Drew, R.A. and M.K. Smith. 1990. Field evaluation of tissue cultured bananas in southeastern Queensland. Austral. J. Exp. Agr. 30:569-574.

Fitch, W.M. 1971. Towards defining the course of evolution: minimal change for a specific tree topology, p. 165. In: D.E. Soltis, P.S. Soltis, and J.J. Doyle (eds.). Molecular systematics of plants II. Kluwer Acad. Publ., London.

Ford-Lloyd, B. 1996. Measuring genetic variation using molecular markers, ver. 1.2. Univ. of Birmingham, Kevin Painting, IPGRI, Rome. p. 31.

Ford-Lloyd, B.V., E. Howell and H.J. Newbury. 1993. An evaluation of random amplified polymorphic DNA (RAPD) as a tool for detecting 
genetic instability in Musa germplasm stored in vitro, p. 375. In: J. Ganry (ed.). Breeding Banana and Plantain for Resistance to Dis. and Pests. Proc. Intl. Symp. Genet. Improvement of Bananas for Resistance to Dis. and Pests, CIRADFLHOR, Montpellier, France, 7-9 Sept. 1992.

Gawel, NJ and R.L. Jarret. 1991. Chloroplast DNA restriction fragment length polymorphisms (RFLP) in Musa species. Theor. Appl. Genet. 81:783-786

Henry, R.J. 1997. Practical applications of plant molecular biology, First ed. Chapman and Hall. Cambridge Univ. Press, U.K. p. 3.

Hwang, S.C. and W.H. Ko. 1987. Somaclonal variation of bananas and screening for resistance of Fusarium wilt, p. 151-156. In: G.J. Persley and E.A. Langhe (eds.). Banana and Plantain Breeding Strategies, Proc. Intl. Wkshp., Cairns, Australia, 13-17 Oct. 1996. ACIAR Proc. No. 21, Canberra, Australia,

Innis, M.A., D.H. Gelfand and, J.J. Sninsky. 1999. PCR Applications: Protocols for functional genomics. Acad. Press, U.K. p. 18.

Jones, D.R. 1999. Diseases of banana, abaca and enset. CABI Publ., Wallingford, U.K.
Liu, C.J. and J.M. Musial. 2001. The application of chloroplast DNA clones in identifying maternal donors for polyploid species of Stylosanthes. Theor. Appl. Genet. 102:73-77.

Lysak, M.A., M. Dolezelova, J.P. Horry, R. Swennen and J. Dolezel. 1999. Flow cytometric analysis of nuclear DNA content in Musa. Theor. Appl. Genet. 98: 1344-1350.

Michaelmore, R.W., I. Paran, and R.V. Kesseli. 1991. Identification of markers linked to disease-resistance genes by bulked segregant analysis: A rapid method to detect markers in specific regions by using segregating populations. Proc. Natl. Acad. Sci. USA. 88:9828-9832.

Nakamura, I., N. Kameya, Y. Kato, S. Yamanaka, H. Jomori, and Y. Sato. 1997. A proposal for identifying the short ID sequence which addresses the plastid subtype of higher plants. Breed. Sci. 7:385-388.

Robinson, J.C. 1996. Bananas and plantains. CAB Intl., U.K. p. 12-29.

Rozen, Steve and H.J. Skaletsky. 1998. Primer 3. Code available at http://www-genome.wi. mit.edu/genomesoftware/other/primer3.html.

Shepherd, K. 1954. Seed fertility of the 'Gros
Michael' banana in Jamaica. J. Hort. Sci. 29:1-11. Simmonds, N.W. 1962. The evolution of bananas, p. 170. In: D.R. Jones (ed.) Diseases of banana, abaca and enset. CABI Publ., Wallingford, U.K. Simmonds, N.W and S.T.C. Weatherup. 1990. Numerical taxonomy of the wild bananas (Musa). New Phytol. 115:567-571.

Stockton, T., G. Sonnante, and P. Gepts. 1992. Detection of minisatellite sequences in Phaseolus vulgaris. Plant Mol. Biol. Rep. 10:47-59.

Stover R.H. 1987. Somaclonal variation in Grand Nain and Saba in the nursery and field, p. 136139. In: Persley, G.J. and E.A. Langhe (eds.). Banana and Plantain Breeding Strategies, Proc Intl. Wkshp., Cairns, Australia, 13-17 Oct. 1996. ACIAR Proc. No. 21, Canberra, Australia,

Williams, J.G.K., K.J. Kubelik, K.J. Livak, J.A. Rafalski, and S.V. Tingey. 1990. DNA polymorphisms amplified by arbitrary primers are useful genetic markers. Nuc. Acid Res. 18:65316535

Winberg, B.C., Z. Zhou, J.F. Dallas, C.L. McIntyre, and J.P. Gustafson. 1993. Characterization of minisatellite sequences from Oryza sativa. Genome 36:978-983. 